\title{
Incidence of clinical isolates and its antimicrobial resistance pattern among the nasal and hand swabs of operation theatre staff in tertiary and secondary care hospitals.
}

\author{
Mohammed Saleem $^{1}$, Irfan Ahmad ${ }^{2,3^{*}}$, Fahaad Alenazi ${ }^{4}$ \\ ${ }^{1}$ Department of Pathology, Division of Microbiology, College of Medicine, University of Hail, Saudi Arabia \\ ${ }^{2}$ Department of Clinical Laboratory Sciences, College of Applied Medical Sciences, King Khalid University, Saudi \\ Arabia \\ ${ }^{3}$ Research Centre for Advanced Material Sciences, King Khalid University, Saudi Arabia \\ ${ }^{4}$ Department of Pharmacology, Pharmacology, College of Medicine, University of Hail, Saudi Arabia
}

\begin{abstract}
The aim of this study is to identify antimicrobial resistance patterns among bacterial isolates causing nosocomial infection among staff of the surgical units of two hospitals in the north Indian setting. This was a cross sectional study design. Samples were obtained from health care givers with the selection criteria of: No previous history of hospitalization, no history of likely contact with patients of Staphylococcus aureus, and the health personnel available in the operation theatre at the time of sample collection. All the specimens were inoculated on sheep blood agar and MacConkey agar media and thereafter incubated at $37^{\circ} \mathrm{C}$ for $24 \mathrm{~h}$ for the bacterial identification. The MRSA was lower among nasal (8.1\%) and hand swabs (6.7\%) than MSSA (nasal=33.9\%, hand=28.3) among surgeons. However, MSSA was $30 \%$ among nasal swabs and $24.1 \%$ among hand swabs in tertiary care hospital. Gram positive bacterial isolates were highly resistant to ampicillin $(98.3 \%)$, amoxy/clav $(95.4 \%)$, active ingredient $(\mathbf{8 2 . 3 \%})$ and tetracycline $\mathbf{7 7 . 1 \%})$ in nasal swab of surgeons and OT health staffs in tertiary care hospital while these were ampicillin $(84.3 \%)$, amoxy/clav $(79.9 \%)$, active ingredient $(68.7 \%)$ and tetracycline $(65.7 \%)$ resistant in secondary care hospital. Gram negative bacterial isolates were highly resistant to ampicillin $(\mathbf{8 8 . 0 \%})$, amoxy/clav, ceftazidime and cefepime $(\mathbf{8 0 . 0 \%})$ each in nasal swab of surgeons and OT health staffs in tertiary care hospital while these were ampicillin $(83.0 \%)$, amoxy/clav $(68.8 \%)$, active ingredient $(61.1 \%)$, ceftazidime and tobramycin $(60.0 \%)$ each resistant in secondary care hospital. The data of the present study demonstrate the widespread problem of antibiotic resistance among staff of surgical units in the two hospitals. Continued surveillance is necessary to guide appropriate empirical therapy for these infections. It is imperative that all professionals take an active role in infection control within their establishments. More resources should be provided to encourage good antibiotic practice and good hygiene in hospitals.
\end{abstract}

Keywords: Nosocomial infection, Bacterial isolates, Antimicrobial resistance, Operation theatre.

Accepted on March 28, 2018

\section{Introduction}

Microbial contamination of hospital environment, especially the operating theatre and other specialized units had continued to increase prevalence of nosocomial infection [1-4]. Nosocomial infections are an important cause of mortality and morbidity in any hospital setting [5]. Of them, infections contracted from doctors occupy a sizeable proportion. Personto-person contact among medical staff and between medical staff and patients appears to be the most common route of transmission of virulent strains like Staphylococcus aureus (including methicillin-resistant Staphylococcus aureus, i.e. MRSA) and pseudomonas [6].

Hospital represents a special environment, providing health care to patients and as a work environment for medical and other staff. One of the important sources of staphylococcus for nosocomial infections is nasal carriage among hospital personnel [7]. Studies on nasal carriage of Coagulase-Negative Staphylococci (CoNS) in Health Care Workers (HCWs) are much lacking. There are a lot of studies on nasal carriage of Staphylococcus aureus and methicillin resistance in $S$. aureus 
among health care workers. Since CoNS are now increasingly recognized as nosocomial pathogens in recent years $[7,8]$.

The infection is usually acquired during the operation itself; either exogenously (e.g. from the air, medical equipment, surgeons and other staff), endogenously from the flora on the skin or in the operative site or, rarely from blood used in surgery. The infecting microorganisms are variable, depending on the type and location of surgery, and antimicrobials received by the patient. The main risk factor is the extent of contamination during the procedure (clean contaminated), which is to a large part dependent on the length of the operation, and the patient's general condition [9]. Personnel and patients can acquire MRSA by coming into contact with a contaminated environment or objects in the environment [10].

Organizational risk factors include contaminated airconditioning systems, contaminated water systems, staff and physical layout of the facility (e.g., nurse-to-patient ratio, open beds close together). Patient risk factors include the severity of illness, underlying immune-compromised state, and length of stay $[11,12]$.

The widespread use of antimicrobials for therapy or prophylaxis (including topical) is the major determinant of resistance. Antimicrobial agents are, in some cases, becoming less effective because of resistance. As an antimicrobial agent becomes widely used, bacteria resistant to this drug eventually emerge and may spread in the health care setting. Multiresistant Klebsiella and Pseudomonas aeruginosa are prevalent in many hospitals. This problem is particularly critical in developing countries where more expensive second-line antibiotics may not be available or affordable [13].

This study aimed to identify antimicrobial resistance patterns among bacterial isolates causing nosocomial infection among staff of the surgical units of two hospitals in the north Indian setting.

\section{Material and Methods}

\section{Study design and study area}

This was the cross sectional study which was conducted in tertiary care hospital (King George's Medical University) and secondary care hospital (Dr. Shyama Prasad Mukherji Hospital (Civil Hospital) of Lucknow.

\section{Determination of the hospital acquisition of nasal carriage and palm of hand of MRSA isolates}

Samples were obtained from health care givers with the selection criteria of:

1. No previous history of hospitalization.

2. No history of likely contact with patients of Staphylococcus aureus.

3. The health personnel available in the operation theatre at the time of sample collection.

\section{Nasal swab}

Nasal swabs were collected from health care givers. The swab was inserted in anterior nasal chamber, $2 \mathrm{~cm}$ into the nares by rotating the swab against the nasal mucosa pre-moistened with saline [14]. This process was repeated on the other side also.

\section{Hand swabs}

Hand swabs were collected from palm of hands of health care givers. This was done by rubbing a sterile swab, on palm of hands [14].

\section{Culture of specimen}

All the specimens were inoculated on sheep blood agar and MacConkey agar media and thereafter incubated at $37^{\circ} \mathrm{C}$ for 24 $\mathrm{h}$, for the bacterial identification [15].

\section{Identification of isolates}

Bacterial isolates was identified with the help of Gram staining and biochemical tests such as catalase, coagulase, oxidase test, IMViC, sugar fermentation, methyl red, voges proskauer and sugar fermentation test etc. Mainly, facultative anaerobes and aerobic bacteria such as Staphylococcus aureus including MRSA, coagulase-negative Staphylococci (CoNS), Acinetobactor species and Pseudomonas aeruginosa were taken into consideration as per guidelines of CLSI [16]. Antimicrobial susceptibility testing was done by the KirbyBauer disc diffusion method [17,18].

\section{Statistical analysis}

The data collected was entered in the Microsoft Excel computer program and checked for any inconsistency. The results are presented in proportions/percentages. The unadjusted and adjusted logistic regression analysis was carried out to find out the relative importance of the factors associated with the NI. The p-value $<0.05$ was considered as significant. All the analysis was carried out by using SPSS 16.0 version.

\section{Ethical clearance and consent}

Ethical clearance was taken from Institutional Ethical Committee of King George's Medical University UP, Lucknow. The consent was taken from the staff of the operation theatre before the collection of specimen.

\section{Results}

\section{Staff of operation theater}

Distribution of different types of isolates among staff of operation theater specimen is depicted in the Table 1. The occurrence of MRSA was higher among nasal $(9.4 \%)$ than hand swabs $(6.5 \%)$ among surgeons in tertiary care hospital. Similar observation was found among OT staff in tertiary care hospital. However, the occurrence of MRSA was lower among 
Incidence of clinical isolates and its antimicrobial resistance pattern among the nasal and hand swabs of operation theatre staff in tertiary and secondary care hospitals

nasal $(6.7 \%)$ than hand swabs $(6.9 \%)$ among surgeons in secondary care hospital. Similar observation was found among OT staff in secondary care hospital.

Table 1. Distribution of different types of isolates among staff of Operation Theater (OT).

\begin{tabular}{|c|c|c|c|c|c|c|c|c|}
\hline \multirow{3}{*}{ Types of isolates } & \multicolumn{4}{|c|}{ Surgeon } & \multicolumn{4}{|c|}{ OT staff } \\
\hline & \multicolumn{2}{|l|}{ Nasal } & \multicolumn{2}{|c|}{ Hand } & \multicolumn{2}{|l|}{ Nasal } & \multicolumn{2}{|l|}{ Hand } \\
\hline & No. & $\%$ & No. & $\%$ & No. & $\%$ & No. & $\%$ \\
\hline Tertiary care & $n=36$ & & $n=38$ & & $n=178$ & & $n=179$ & \\
\hline Bacillus spp. & 3 & 9.4 & 12 & 38.7 & 11 & 6.2 & 51 & 28.5 \\
\hline $\mathrm{CoNS}^{1}$ & 11 & 34.4 & 6 & 19.4 & 55 & 30.9 & 37 & 20.7 \\
\hline Acinetobacter Iwoffi & 1 & 3.1 & 2 & 6.5 & 6 & 3.4 & 19 & 10.6 \\
\hline Acinetobacter baumannii & 1 & 3.1 & 3 & 9.7 & 7 & 3.9 & 12 & 6.7 \\
\hline MRSA & 3 & 9.4 & 2 & 6.5 & 20 & 11.2 & 12 & 6.7 \\
\hline MSSA & 12 & 37.5 & 10 & 32.3 & 74 & 41.6 & 56 & 31.3 \\
\hline Klebsiella ozaenae & 5 & 15.6 & 1 & 3.2 & 25 & 14 & 8 & 4.5 \\
\hline Pseudomonas aeruginosa ${ }^{2}$ & 0 & 0 & 2 & 6.5 & 5 & 2.8 & 22 & 12.3 \\
\hline Secondary care & $n=30$ & & $n=29$ & & $n=143$ & & $n=138$ & \\
\hline Bacillus spp. & 2 & 6.7 & 8 & 27.6 & 9 & 6.3 & 35 & 25.4 \\
\hline $\mathrm{CoNS}^{1}$ & 13 & 43.3 & 12 & 41.4 & 47 & 32.9 & 41 & 29.7 \\
\hline Acinetobacter Iwoffi & 1 & 3.3 & 3 & 10.3 & 11 & 7.7 & 11 & 8 \\
\hline Acinetobacter baumannii & 1 & 3.3 & 1 & 3.4 & 5 & 3.5 & 13 & 9.4 \\
\hline MRSA & 2 & 6.7 & 2 & 6.9 & 10 & 7 & 10 & 7.2 \\
\hline MSSA & 9 & 30 & 7 & 24.1 & 53 & 37.1 & 49 & 35.5 \\
\hline Klebsiella ozaenae & 5 & 16.7 & & 0 & 25 & 17.5 & 7 & 5.1 \\
\hline Pseudomonas aeruginosa ${ }^{2}$ & 1 & 3.3 & 4 & 13.8 & 4 & 2.8 & 18 & 13 \\
\hline Total & $n=62$ & & $n=60$ & & $n=321$ & & $n=317$ & \\
\hline Bacillus spp. & 5 & 8.1 & 20 & 33.3 & 20 & 6.2 & 86 & 27.1 \\
\hline CoNS & 24 & 38.7 & 18 & 30 & 102 & 31.8 & 78 & 24.6 \\
\hline Acinetobacter Iwoffi & 2 & 3.2 & 5 & 8.3 & 17 & 5.3 & 30 & 9.5 \\
\hline Acinetobacter baumannii & 2 & 3.2 & 4 & 6.7 & 12 & 3.7 & 25 & 7.9 \\
\hline MRSA & 5 & 8.1 & 4 & 6.7 & 30 & 9.3 & 22 & 6.9 \\
\hline MSSA & 21 & 33.9 & 17 & 28.3 & 127 & 39.6 & 105 & 33.1 \\
\hline Klebsiella ozaenae & 10 & 16.1 & 1 & 1.7 & 50 & 15.6 & 15 & 4.7 \\
\hline Pseudomonas aeruginosa & 1 & 1.6 & 6 & 10 & 9 & 2.8 & 40 & 12.6 \\
\hline
\end{tabular}

1Surgeon: Hand $p<0.0001$; ${ }^{2}$ Surgeon: Hand $p=0.001$.

Table 2. Percentage of gram positive and negative bacterial isolate resistant to antimicrobial agents among surgeon and OT health staff-Nasal swab.

Antimicrobial agents
Gram negative

p-value Tertiary care Secondary care

p-value 


\begin{tabular}{|c|c|c|c|c|c|c|c|c|c|c|}
\hline & $\begin{array}{l}\text { No. of } \\
\text { isolates }\end{array}$ & $\begin{array}{l}\text { No. resistant } \\
(\%)\end{array}$ & $\begin{array}{l}\text { No. of } \\
\text { isolates }\end{array}$ & $\begin{array}{l}\text { No. resistant } \\
(\%)\end{array}$ & $\begin{array}{l}\text { No. of } \\
\text { isolates }\end{array}$ & $\begin{array}{l}\text { No. } \\
\text { resistant } \\
(\%)\end{array}$ & $\begin{array}{l}\text { No. of } \\
\text { isolates }\end{array}$ & $\begin{array}{l}\text { No. } \\
\text { resistant } \\
(\%)\end{array}$ & & \\
\hline Ampicilin & 175 & $172(98.3)$ & 134 & $113(84.3)$ & $0.04^{*}$ & 50 & $44(88.0)$ & 53 & $44(83.0)$ & 0.12 \\
\hline Amoxy/Clav & 175 & $167(95.4)$ & 134 & $107(79.9)$ & $0.03^{*}$ & 45 & $36(80.0)$ & 48 & $33(68.8)$ & 0.05 \\
\hline Piperacillin/Tazobactum & - & - & - & - & & 20 & $7(35.0)$ & 23 & $6(26.1)$ & $0.03^{*}$ \\
\hline Cefotaxime & - & - & - & - & & 45 & $29(64.4)$ & 48 & $27(56.3)$ & 0.06 \\
\hline Ceftriaxone & - & - & - & - & & 30 & $21(70.0)$ & 30 & $16(53.3)$ & $0.02^{*}$ \\
\hline Ceftazidime & - & - & - & - & & 5 & $4(80.0)$ & 5 & $3(60.0)$ & $0.01^{*}$ \\
\hline Cefepime & - & - & - & - & & 5 & $4(80.0)$ & 5 & $2(40.0)$ & $0.01^{*}$ \\
\hline Cefaperazone/Sulbactum & - & - & - & - & & 50 & $28(56.0)$ & 53 & $21(39.6)$ & $0.01^{*}$ \\
\hline Imipenem & - & - & - & - & & 50 & $18(36.0)$ & 53 & $10(18.9)$ & $0.01^{*}$ \\
\hline Gentamicin & - & - & - & - & & 50 & $33(66.0)$ & 53 & $31(58.5)$ & 0.09 \\
\hline Amikacin & - & - & - & - & & 50 & $29(58.0)$ & 53 & $23(43.4)$ & 0.06 \\
\hline Ciprofloxacin & - & - & - & - & & 15 & $8(53.3)$ & 18 & $8(44.4)$ & 0.05 \\
\hline Levofloxacin & 175 & $83(47.4)$ & 134 & $47(35.1)$ & $0.03^{*}$ & 35 & $22(62.9)$ & 35 & $18(51.4)$ & 0.05 \\
\hline Vancomycin & 175 & $0(0.0)$ & 134 & $0(0.0)$ & - & - & - & - & - & \\
\hline Active ingredient & 175 & $144(82.3)$ & 134 & $92(68.7)$ & $0.01^{*}$ & 15 & $10(66.7)$ & 18 & $11(61.1)$ & 0.11 \\
\hline Tetracycline & 175 & $135(77.1)$ & 134 & $88(65.7)$ & $0.04^{*}$ & 15 & $10(66.7)$ & 18 & $9(50.0)$ & 0.12 \\
\hline Erythromycin & 175 & $121(69.1)$ & 134 & 73 (54.5) & 0.06 & - & - & - & - & \\
\hline Meropenem & - & - & - & - & & 50 & $19(38.0)$ & 53 & 10 (18.9) & $0.01^{*}$ \\
\hline Clindamycin & 175 & $113(64.6)$ & 134 & $62(46.3)$ & $0.01^{*}$ & - & - & - & - & \\
\hline Oxacillin & 175 & $51(29.1)$ & 134 & $30(22.4)$ & 0.11 & - & - & - & - & \\
\hline Linezolid & 175 & $11(6.3)$ & 134 & $2(1.5)$ & 0.06 & - & - & - & - & \\
\hline Tobramycin & - & - & - & - & & 5 & $3(60.0)$ & 5 & $3(60.0)$ & 1 \\
\hline Colistin & - & - & - & - & & 5 & $2(40.0)$ & 5 & $2(40.0)$ & 1 \\
\hline Norfloxacin & 175 & $80(45.7)$ & 134 & $55(41.0)$ & 0.13 & 50 & $28(56.0)$ & 53 & $24(45.3)$ & 0.09 \\
\hline
\end{tabular}

*Significant between tertiary and secondary care hospital.

Table 3. Percentage of gram positive and negative bacterial isolate resistant to antimicrobial agents among surgeon and OT health staff-Hand swab.

\begin{tabular}{|c|c|c|c|c|c|c|c|c|c|c|}
\hline \multirow{3}{*}{ Antimicrobial agents } & \multicolumn{5}{|c|}{ Gram positive } & \multicolumn{5}{|c|}{ Gram negative } \\
\hline & \multicolumn{2}{|c|}{ Tertiary care } & \multicolumn{2}{|c|}{ Secondary care } & p-value & \multicolumn{2}{|c|}{ Tertiary care } & \multicolumn{2}{|c|}{ Secondary care } & \multirow[t]{2}{*}{$p$-value } \\
\hline & $\begin{array}{l}\text { No. of } \\
\text { isolates }\end{array}$ & $\begin{array}{l}\text { No. resisters } \\
(\%)\end{array}$ & $\begin{array}{l}\text { No. of } \\
\text { isolates }\end{array}$ & $\begin{array}{l}\text { No. } \\
\text { resisters } \\
(\%)\end{array}$ & $\begin{array}{l}\text { No. of } \\
\text { isolates }\end{array}$ & $\begin{array}{l}\text { No. } \\
\text { resistant } \\
(\%)\end{array}$ & $\begin{array}{l}\text { No. of } \\
\text { isolates }\end{array}$ & $\begin{array}{l}\text { No. } \\
\text { resisters } \\
(\%)\end{array}$ & & \\
\hline Ampicillin & 123 & $115(93.5)$ & 121 & $98(81.0)$ & 0.1 & 69 & $64(92.7)$ & 57 & $47(82.4)$ & $0.04^{*}$ \\
\hline Amoxy/Clav & 123 & $109(88.6)$ & 121 & $91(75.2)$ & 0.02 & 45 & $34(75.5)$ & 35 & $21(60.0)$ & $0.03^{*}$ \\
\hline Piperacillin/Tazobactum & - & - & - & - & & 60 & $31(51.6)$ & 50 & $21(42.0)$ & 0.06 \\
\hline Cefotaxime & - & - & - & - & & 45 & $32(71.1)$ & 35 & $20(57.1)$ & $0.01^{*}$ \\
\hline Ceftriaxone & - & - & - & - & & 9 & $6(66.6)$ & 7 & $3(42.8)$ & $0.01^{*}$ \\
\hline
\end{tabular}


Incidence of clinical isolates and its antimicrobial resistance pattern among the nasal and hand swabs of operation theatre staff in tertiary and secondary care hospitals

\begin{tabular}{|c|c|c|c|c|c|c|c|c|c|c|}
\hline Ceftazidime & - & - & - & - & & 24 & $\begin{array}{ll}17 & (70.8) \\
(72.4)\end{array}$ & 22 & $13(59.0)$ & $0.01^{*}$ \\
\hline Cefepime & - & - & - & - & & 24 & $16(66.6)$ & 22 & $12(54.5)$ & 0.05 \\
\hline Cefaperazone/Sulbactum & - & - & - & - & & 69 & $39(56.5)$ & 57 & $24(42.1))$ & $0.04^{*}$ \\
\hline Imipenem & - & - & - & - & & 69 & $26(37.6)$ & 57 & $11(19.3)$ & $0.01^{*}$ \\
\hline Gentamicin & - & - & - & - & & 69 & $50(72.4)$ & 57 & $36(63.1)$ & 0.11 \\
\hline Amikacin & - & - & - & - & & 69 & $32(46.3)$ & 57 & $22(38.6)$ & 0.07 \\
\hline Ciprofloxacin & - & - & - & - & & 36 & $19(52.7)$ & 28 & $12(42.8)$ & $0.04^{*}$ \\
\hline Levofloxacin & 123 & $62(50.4)$ & 121 & $57(47.1)$ & 0.11 & 33 & $18(54.5)$ & 29 & $13(44.8)$ & $0.04^{*}$ \\
\hline Vancomycin & 123 & $0(0.0)$ & 121 & $0(0.0)$ & - & - & - & - & - & \\
\hline Active ingredient & 123 & $95(77.2)$ & 121 & $77(63.6)$ & 0.1 & 36 & $25(69.4)$ & 28 & $18(64.2)$ & 0.09 \\
\hline Tetracycline & 123 & $91(74.0)$ & 121 & $73(60.3)$ & $0.02^{*}$ & 45 & $34(75.5)$ & 35 & $22(62.8)$ & $0.04^{*}$ \\
\hline Erythromycin & 123 & $84(68.3)$ & 121 & $49(40.5)$ & $0.01^{*}$ & - & - & - & - & \\
\hline Meropenem & - & - & - & - & & 69 & $22(31.8)$ & 57 & $14(24.5)$ & $0.03^{*}$ \\
\hline Clindamycin & 123 & $74(60.2)$ & 65 & $23(35.4)$ & $0.01^{*}$ & - & - & - & - & \\
\hline Oxacillin & 123 & $22(17.9)$ & 121 & $19(15.7)$ & 0.23 & - & - & - & - & \\
\hline Linezolid & 123 & $1(0.8)$ & 121 & $1(0.8)$ & 1 & - & - & - & - & \\
\hline Tobramycin & - & - & - & - & & 24 & $17(70.8)$ & 22 & $13(59.0)$ & $0.02^{*}$ \\
\hline Colistin & - & - & - & - & & 24 & $11(45.8)$ & 22 & $6(27.2)$ & $0.01^{*}$ \\
\hline Norfloxacin & 123 & $63(51.2)$ & 121 & $53(43.8)$ & 0.12 & 69 & $38(55.0)$ & 57 & $25(43.8)$ & $0.04^{*}$ \\
\hline
\end{tabular}

*Significant between tertiary and secondary care hospital.

Table 2 shows that Gram positive bacterial isolates were highly resistant to ampicillin (98.3\%) and amoxy/clav (95.4\%) in nasal swab of both surgeons and OT staff in tertiary care hospital. Almost similar observation was found in secondary care hospital. Gram negative bacterial isolates were also highly resistant to ampicillin and amoxy/clav in nasal swab of both surgeons and OT staff in tertiary and secondary care hospitals

Table 3 shows that gram positive bacterial isolates were highly resistant to ampicillin (93.5\%) and amoxy/clav in hand swab of surgeons and OT health staffs in tertiary care hospital. Almost similar observation was found in secondary care hospital. Gram negative bacterial isolates were also highly resistant to ampicillin and amoxy/clav in hand swab of both surgeons and OT staff in tertiary and secondary care hospitals.

\section{Discussion}

In that countries where resources are limited, surgical site infections remain a major cause of nosocomial infections [19]. This study therefore mainly targeted on the staff of surgery units. The study presents evident limitations but, since samples were collected by staff from the staff of the institute to ensure their rapid delivery to the laboratory.

Gram negative bacteria cause thousands of hospital acquired infections each year. It is estimated that approximately $30 \%$ of all the hospital acquired infections are caused by gram negative bacteria and that they are responsible for approximately $70 \%$ of all hospital acquired infections in the Intensive Care Unit [20].

In the present study, MRSA was lower among nasal and hand swab than MSSA among surgeons. Similar observation was found among OT staff in this study. The MRSA was $6.7 \%$ among nasal swab and $6.5 \%$ among hand swab in tertiary care hospital in the present study. However, MSSA was 30\% among nasal swab and $24.1 \%$ among hand swab in tertiary care hospital in this study. Almost similar pattern was found in secondary care hospital. The CoNS was statistically significantly $(p<0.0001)$ different among hand swab of surgeon between tertiary and secondary care hospitals. However, Pseudomonas aeruginosa was significantly different among the hand swab of surgeons between tertiary and secondary care hospitals in this study.

MRSA was found on uniforms and gowns of $65 \%$ of healthcare workers performing care activities for patients with MRSA and $42 \%$ of healthcare workers having contact only with the environment in an MRSA patient's room had MRSA on their gloves [2]. In a study, it was reported that only $6.67 \%$ (4 out of 60 samples) of the positive swabs were from samples that were collected from hospital personnel [21]. It had been 
reported that $73 \%$ staff members of a hospital were using gloves including $67 \%$ of physicians and $78 \%$ of nurses [22].

This study provides insights into the problem of resistance in bacterial pathogens among the staff of surgical units in the tertiary and secondary care hospitals. Our results demonstrated that, in general, isolates have high rates of resistance to antibiotics commonly used in developing countries. We also found a high rate of resistance to penicillin, first generation cephalosporins and cotrimoxazol. Therefore, cheap antibiotics such as amoxicillin, tetracyclin and cotrimoxazol are now of limited benefit in the treatment of infections in the hospitals. These results, probably due to overuse of broad-spectrum antibiotics, confirm those of previous studies $[23,24]$.

\section{Conclusions}

The data of the present study demonstrate the widespread problem of antibiotic resistance among staff of surgical units in the tertiary and secondary care hospitals. Continued surveillance is necessary to guide appropriate empirical therapy for these infections. It is imperative that all professionals take an active role in infection control within their establishments. More resources should be provided to encourage good antibiotic practice and good hygiene in hospitals.

\section{References}

1. Bonten MJM, Hayden MK, Nathan C. Epidemiology of colonsation of patient and environment with vancomycinresistant enterococci. Lancet 1996; 348: 1615-1619.

2. Boyce JM, Potter-Bynoe G, Chenevert C, King T. Environmental contamination due to methicillin-resistant Staphylococcus aureus: Possible infection control implications. Infect Control Hosp Epidemiol 1997; 18: 622-627.

3. Hayden MK, Bonten MJ, Blom DW, Lyle EA, van de Vijver DA. Reduction in acqusation of vancomycinresistant Enterococcus after enfourcement of routine environment cleaning measures. Clin Infect Dis 2006; 42: 1552-1560.

4. Bhalla A, Drin, D., Donskey CJ. Staphylococcus aureus intestinal colonization in associated with increased frequency of S. aureus on skin of hospitalized patients BMC Infect Dis 2007; 7: 108-123.

5. Ducel J, Fabry L, Nicolle G. Prevention of hospital acquired infections: A practical guide (2nd Ed.) WHO 2002.

6. Schaberg DR, Culver DH, Gaynes RP. Major trends in the microbial etiology of nosocomial infection. Am J Med 1991; 91: 72-75.

7. Farzana K, Rashid Z, Akhatar N, Sattar A, Khan JA, Nasir B. Nasal carriage of staphylococci in health care workers: Anti-microbial susceptibility profile. Pak J Pharm Sci 2008; 21: 290-294.

8. Nowak T, Balcerczak E, Mirowski M, Szewczyk EM. Detection of methicillin resistance in hospital environmental strains of coagulase negative Staphylococci. Polish J Microbiol 2006; 55: 339-343.

9. Kirkland KB. The impact of surgical-site infections in the 1990's: attributable mortality, excess length of hospitalization and extra costs. Infect Control Hosp Epidemiol 1999; 20: 725-730.

10. Martinez J, Ruthazer R, Hansjosten K, Barefoot L, Snydman D. Role of environmental contamination as a risk factor for acquisition of vancomycin-resistant enterococci in patients treated in a medical intensive care unit. Arch Intern Med 2003; 163: 1905-1912.

11. Nguyen QV. Hospital acquired infections. Emedicine 2004.

12. Asefzadeh M. The risk of nosocomial infections for NCD patients. NCD Malaysia 2005; 4: 8-12.

13. Proceedings of the 3rd Decennial International Conference on Nosocomial Infections, Preventing Nosocomial Infections. Progress in the 80's. Plans for the 90's, Atlanta, Georgia 1990; 30.

14. Miller J. Michael Ed. A guide to specimen management in clinical microbiology (2nd Edition). Am Society Microbiol 1999; 1-61.

15. Watt B, Miles RS, Colle JG. Test for identification of bacteria. Pract Med Microbiol 1996; 131-150.

16. Clinical and Laboratory Standards Institute (CLSI). Abbreviated identification of bacteria and yeast; approved guideline-second edition. Clinical Laboratory Standards Institute 2008.

17. Bauer AW, Kirby WM, Sherris JC, Turck M. Antibiotic susceptibility testing by a standardized single disk method. Am J Clin Pathol 1966; 36: 493-496.

18. Clinical and Laboratory Standards Institute (CLSI). Performance standards for antimicrobial disk susceptibility tests (15th Ed.). Clinical and Laboratory Standards Institute, Wayne, PA, USA 2009; 25: M02-A10.

19. Probhakar P, Roje D, Castle D, Rat B, Fletcher P, Duquesnay D. Nosocomial surgical infections: incidence and cost in a developing country. Am J Infect Control 1983; 11: 51-56.

20. Peleg, Anton Y, David CH. Hospital-acquired infections due to gram negative bacteria. New England J Med 2010; 362: 1804-1813.

21. Nahed AL. Prevalence of bacterial contamination in general operating theatres in selected hospitals in the Gaza Strip, Palestine. J Infect Public Health 2012; 5: 43-51.

22. Manian FA, Ponzillo JJ. Compliance with routine use of gowns by healthcare workers (HCWs) and non-HCW visitors on entry into the rooms of patients under contact precautions. Infect Control Hosp Epidemiol 2007; 28: 337-340.

23. Randrianirina F, Soares JL, Ratsima E, Carod JF, Combe P, Grosjean P. In vitro activities of 18 antimicrobial agents against Staphylococcus aureus isolates from the Institut Pasteur of Madagascar. Ann Clin Microbiol Antimicrobials 2007; 6: 5 .

24. Randrianirina F, Soares JL, Carod JF, Ratsima E, Thonnier $\mathrm{V}$, Combe P. Antimicrobial resistance among uropathogens 
Incidence of clinical isolates and its antimicrobial resistance pattern among the nasal and hand swabs of operation theatre staff in tertiary and secondary care hospitals

that cause community-acquired urinary tract infections in Antananarivo, Madagascar. J Antimicrob Chemother 2007; 59: 309-312.

\section{*Correspondence to}

Irfan Ahmad

Department of Clinical Laboratory Sciences

College of Applied Medical Sciences

King Khalid University

Saudi Arabia 